\title{
COPD transitions in health and self-management: service users' experiences from everyday life
}

This article was published in the following Dove Press journal: International Journal of COPD

\author{
Anne-Grethe Halding' \\ Evy Irene Aarsheim ${ }^{2}$ \\ Nina Marie Dolmen ${ }^{3}$ \\ Aud Jenny Jensen ${ }^{4}$ \\ Sissel Stavøstrand ${ }^{5}$ \\ Ellen Karine Grov' \\ 'Faculty of Health and Social Sciences, \\ Western Norway University of \\ Applied Sciences, Førde, Norway; \\ ${ }^{2}$ Flora Municipality Service, \\ Department of Health, Florø, Norway; \\ ${ }^{3}$ Service User Representative, Årdal, \\ Norway; ${ }^{4}$ Service User Representative, \\ Jølster, Norway; ${ }^{5}$ Service User \\ Representative, Florø, Norway
}

Purpose: To explore how persons living with COPD experience transitions related to health, self-management, and follow-up from the healthcare services.

Patients and methods: This study is part of a participatory research project. Six males and five females living with COPD, with a COPD assessment test score of 21-29, participated; all the participants were living at home. Data were collected in qualitative research interviews and analyzed using qualitative content analysis highlighting the participants' experiences.

Results: The findings showed two main themes: "The struggle to keep going" and "The need for continuity and competent facilitation". The participants reported complex health transitions, with changes in roles and function, demanding exacerbations and critical events, and challenges with learning needed self-management. They expressed a great need for and had great benefit from, education, rehabilitation, and follow-up in their management of everyday life. Not all received offers in line with current guidelines.

Conclusion: In-depth knowledge of patients' experienced COPD transitions offers clinicians guidance for the timing and quality of follow-up services. Life with COPD entails challenging transitions in health and self-management. Good rehabilitation and follow-up from the healthcare services are needed throughout the disease trajectory. Participation in self-management education and rehabilitation that include psychosocial aspects may facilitate health-enhancing transitions and improve self-management skills. Experienced lack of competence and flexibility among healthcare providers hinders trust and collaboration. Access to stable and competent follow-up in the primary health services may facilitate cohesive services and collaborative self-management.

Keywords: COPD, participatory research, qualitative interviews, rehabilitation, follow-up services

\section{Introduction}

People who develop chronic diseases usually experience extensive changes to their daily lives, known as transitions in literature; these are personal processes during which people are particularly vulnerable. Such transitions occur in interaction with the surroundings, an interaction which may hinder or enhance healthy transitions and self-management. ${ }^{1,2}$ Only through good collaboration with the healthcare services at a person and systems level can those living with chronic diseases be active partners in the follow-up of the disease and be supported throughout these demanding transitions. ${ }^{3-6}$

In Norway, 6\% of all reported deaths in 2014 were related to COPD. ${ }^{7}$ The disease thus represents a great challenge to the individual and to the society. ${ }^{8,9}$ Medical treatment needs to be individualized and directed toward reducing symptoms and episodes of exacerbation, as well as toward improving health and physical functioning. The changes in health and function related to COPD also demand that the person living with
Correspondence: Anne-Grethe Halding Western Norway University of Applied Sciences, Høgskulen på Vestlandet, Postbox 7030, 5020 Bergen, Norway Tel +47 48I29603 Email anne.halding@hvl.no (c) (1) (5) 2018 Halding et al. This work is published and licensed by Dove Medical Press Limited. The full terms of this license are available at https://www.dovepress.com/terms.php cc) hereby accept the Terms. Non-commercial uses of the work are permitted without any further permission from Dove Medical Press Limited, provided the work is properly attributed. For permission for commercial use of this work, please see paragraphs 4.2 and 5 of our Terms (https://www.dovepress.com/terms.php). 
the disease learns, takes charge of, and carries out daily disease-specific self-management. The recommendations are thus rehabilitation, education and support for self-management, follow-up, and consultations throughout a changing disease trajectory. ${ }^{6,10}$

The Coordination Reform ${ }^{11}$ was implemented in Norway in 2011, with the aim to improve coordination in the healthcare services and achieve cohesive treatment trajectories for the individual patient, as well as the transfer of more follow-up of chronically ill patients to the municipal healthcare services. The Norwegian national guidelines for the prevention, diagnosis, and treatment of COPD were revised in $2012 .{ }^{10}$ The recommended rehabilitation programs and self-management education in Norway are based on international guidelines ${ }^{6}$ and have two axes: as education, physical training, and support for inpatients in the specialist health care service; and as support, education, physical training, and supervision in groups for outpatients (in the so-called "learning and coping centers") in the specialist health care service or the communities. Not much is known about how people who live with COPD in Norway experience such follow-up and coordination following the Coordination Reform. And not enough is known about their experiences with transitions, and what enhances or hinders self-management and health transitions in a COPD trajectory. We, therefore, conducted a participatory research project to explore how persons living with COPD experience transitions related to health, self-management, and follow-up from the healthcare services. The article communicates findings from individual qualitative interviews, analyzed and discussed in light of theory on transitions in chronic diseases ${ }^{2}$ and collaborative self-management. ${ }^{3,4,12}$

Meleis et al have developed a theory on human transitions, on how people in interaction with their surroundings must adapt to changes that arise from diseases. ${ }^{1,2}$ Transitions are the changes between what was before and what is about to develop, a period that can cause stress and has in it the potential both for growth and regression. Transitions are about how people over time adapt to new situations, periods during which social support, critical events, and health interventions may have a great impact on process and result. ${ }^{13,14}$

Transitions related to health and disease are often quite complex and multidimensional, with, however, some common characteristics: commitment, awareness of change and difference, and critical moments and events. Some claim that the person must, to a certain degree, acknowledge that things are about to change to enter transition, and that such acknowledgment has an impact on the commitment to being active in the situation. Having a chronic disease generally implies having to accept being different, feeling different, and being considered different, and interacting with the surroundings in a new way. These processes happen over time, often repetitively and without clearly defined phases, and with critical turning points. ${ }^{2}$ An important personal transition is the change to patienthood, when one is in danger of losing one's earlier personal identity. ${ }^{15}$ The conditions surrounding the individual during such transitions may be divided into what enhances and what hinders a good process. Important phenomena are the meaning the person attaches to the changes, cultural norms, and socioeconomic status, and to what extent the person is prepared and has knowledge to meet the changes. Society's views on an illness, such as stigmatization and marginalization, access to financial and social support, role models, knowledge, and healthcare services, are often crucial elements in personal transitions. ${ }^{1,2}$ Persons living with COPD have experienced that the healthcare services are able to accommodate health-enhancing transitions when they experience common understanding and social support and feel confident with regard to getting help. ${ }^{5,16}$ Difficulties in the communication between patients and health-care personnel and an experience of stigmatization may hinder beneficial processes. ${ }^{17-19}$ Identification of transitions and vulnerable phases and knowledge on what may further enhance or hinder good transitions are important in order to understand the conditions for collaborative selfmanagement. Development of self-management may in that respect be central to the experience of transitions. ${ }^{20}$

Disease-specific self-management and self-management education are central to COPD care. In self-management education, the emphasis is on involving, motivating, and guiding persons to plan their lives and develop skills in order to live as good as possible with the disease. ${ }^{3,6,21}$ The concept of self-management incorporates self-monitoring, symptom management, management of emotional, psychosocial, and functional consequences of a disease, and collaboration with family, community, and healthcare professionals. Self-management abilities are supposed to be mediated by the person's self-efficacy. ${ }^{22}$ Main elements of self-management in chronic disease are the handling of medical treatment and guidelines, the new role, and emotional reactions. Skills must be acquired to recognize and handle exacerbation, and for problem solving, making decisions, and using available resources. ${ }^{4,12}$ Education should be adapted to the individual and his or her phase in the trajectory and contain information related to the disease in question. ${ }^{3}$ Implementation of self-management in the case of COPD is a complex process, 
dependent on the patient, healthcare personnel, and the organization of the healthcare services. ${ }^{23}$ Self-management education may in the short-term secure improved health and functional level, reduce hospital admissions, and give people living with COPD the experience of improved management. ${ }^{24-26}$ Poor health status, anxiety, and conversations with healthcare personnel that strongly focus on disease monitoring are negatively associated with self-management activation among people living with COPD. . 22,27,28 $^{2}$

Summed up, this shows that health transitions, which require change and education, and implementation of COPD self-management are complex processes where the person's interaction with the surroundings, the healthcare services, in particular, seems to be of great importance. We have not found any recommendations for valid and reliable instruments for assessing self-management in COPD. ${ }^{29}$ Since we lack knowledge on these processes in a Norwegian COPD context in a time of reforms, we have posed the following research questions:

- What are central experiences of transitions in health and self-management for people living with COPD?

- What, in the collaboration with the healthcare services, do people who live with COPD experience as enhancing and hindering their transitions?

\section{Methods}

The study is part of a larger participatory research ${ }^{30}$ project, with strong user involvement, in order to develop relevant research questions, enhance good dialogues during interviews, and improve the credibility of analyses and reports. ${ }^{31,32}$ We are not aware that this methodology has been used in the COPD field previously. The project group consisted of four users, recruited through patient organizations and networks, one nurse and one ergo-therapist who worked in a COPD rehabilitation service (users and health workers will in the following be called co-researchers), and three researchers with research experience with user involvement and chronic disease. To secure optimal equal participation, we carried out a co-researcher course with theory of science and methods in parallel with the development of the research project. We emphasized the social learning process and social collaboration throughout the process, ${ }^{33,34}$ in addition to training in interview situations. The co-researchers were actively involved in the development of research focus and research questions, development of interview guide, recruitment, and in data collection, analysis, and reporting. In collaboration, we decided to conduct a qualitative interview study. Qualitative research aims to explore the context bound and nuanced qualitative descriptions of different aspects of human experiences by systematic collection and interpretation of textual material. ${ }^{35}$ Qualitative research interviews, structured professional conversations with few interviewees about their daily lives, were planned and performed in accordance with Kvale's ${ }^{36}$ recommendations, to gain deeper insight into the participants' experiences with health transitions and their interaction with the healthcare services. As Rowan and Huston put the purpose, results from qualitative research “provides insight into what peoples' experiences are, why they do what they do, and what they need in order to change" to make "an important contribution to our understanding of health, the illness experience and effective healthcare" (p. 1442). ${ }^{37}$

The population consisted of persons registered with COPD as main or secondary diagnosis in a health unit in rural Norway. Through purposeful sampling, ${ }^{37}$ we chose persons who suffered from significant COPD symptoms, defined with a COPD assessment test (CAT) score of 21-29 (where CAT is an approved translation into Norwegian; GlaxoSmithKline). According to the Norwegian guidelines, ${ }^{10}$ these persons should have been offered follow-up services, and we chose participants who lived in different communities regarding number of inhabitants. During the interviews, we emphasized open dialogues assisted by the interview guide. The main questions in the interview guide were: How is everyday life with COPD (challenges and self-management)? Have you received any follow-up from the healthcare services? What is your view of the follow-up you have received?

The interviews lasted 45-90 minutes and were conducted in the participants' homes or in the authors' workplace, in accordance with the participants' wishes. All co-researchers participated in interviews with the first author. The interviews were recorded as audio files, transcribed by the first author, and safely stored. We ended the data collection after 11 interviews as we decided that the data contained great richness and variation. ${ }^{36}$ A qualitative content analysis with search for manifest and latent meanings ${ }^{38}$ was performed in several steps, and the co-researchers participated in the analysis process. In order to catch the impressions of the whole (step 1), all interviewers read closely the interviews they had participated in. The co-researchers' impressions were communicated orally or in writing to the first author, who imported their perspectives and the transcriptions into NVivo Pro (QSR International). Each interview constituted one unit of analysis and was deconstructed into units of meaning (step 2) and fields of content and tentative categories (step 3, the manifest meanings), before these were discussed in the 
Table I Examples of development from units of meaning to themes

\begin{tabular}{|c|c|c|c|c|c|}
\hline \multicolumn{6}{|c|}{ COPD transitions in health and self-management } \\
\hline Units of meaning & Code & Subcategory & Category & Subtheme & Themes \\
\hline $\begin{array}{l}\text { "I was quite involved before, } \\
\text { volunteering and hunting and fishing and } \\
\text { all, this is all over now, when I can no } \\
\text { longer keep up I feel like a burden." } \\
\text { "I'm just not using the oxygen. I was } \\
\text { really clear on this [...]." }\end{array}$ & Being a burden & $\begin{array}{l}\text { Obstacle to social } \\
\text { participation }\end{array}$ & $\begin{array}{l}\text { Activity } \\
\text { and social } \\
\text { participation }\end{array}$ & $\begin{array}{l}\text { Challenges related } \\
\text { to changing social } \\
\text { role and function }\end{array}$ & $\begin{array}{l}\text { The struggle } \\
\text { to keep going }\end{array}$ \\
\hline $\begin{array}{l}\text { "I'm not going to sit there, in public, } \\
\text { with that thing up my nose and eat. It's } \\
\text { probably stupid of me [...]." }\end{array}$ & $\begin{array}{l}\text { Not be seen with } \\
\text { oxygen }\end{array}$ & Accepting aids & & & \\
\hline $\begin{array}{l}\text { "There was a lot of trauma related } \\
\text { to all the admissions. It was all very } \\
\text { tiring, and [...] I suffered a lot from } \\
\text { depression and anxiety, and last time } \\
\text { three years ago, I was so sick I had one } \\
\text { and a half foot in the grave. The doctors } \\
\text { said there wasn't much they could do. } \\
\text { I fought and fought." } \\
\text { "I tried to make myself so small they } \\
\text { wouldn't notice me." }\end{array}$ & $\begin{array}{l}\text { Traumatic and } \\
\text { fatiguing hospital } \\
\text { admission }\end{array}$ & $\begin{array}{l}\text { Experience of } \\
\text { admission }\end{array}$ & $\begin{array}{l}\text { Hospital } \\
\text { admission }\end{array}$ & $\begin{array}{l}\text { Demanding } \\
\text { exacerbations and } \\
\text { critical events }\end{array}$ & \\
\hline $\begin{array}{l}\text { "I've woken up during the night and not } \\
\text { been able to breathe. Well, it is a bit } \\
\text { scary, isn't it, when you can't breathe." }\end{array}$ & $\begin{array}{l}\text { Scary not to be able } \\
\text { to breathe }\end{array}$ & $\begin{array}{l}\text { Consequences } \\
\text { of breathing } \\
\text { problems }\end{array}$ & $\begin{array}{l}\text { Symptom } \\
\text { burden }\end{array}$ & & \\
\hline $\begin{array}{l}\text { "There are several things. One is that at } \\
\text { home you get to choose whether you } \\
\text { want to get on the treadmill or not. But } \\
\text { there you just have to every morning. } \\
\text { It gives sort of a kick-start, [...]." }\end{array}$ & $\begin{array}{l}\text { Kick-starting } \\
\text { exercise }\end{array}$ & $\begin{array}{l}\text { Outcome of } \\
\text { rehabilitation }\end{array}$ & $\begin{array}{l}\text { When } \\
\text { rehabilitation is } \\
\text { good and when } \\
\text { it is missing }\end{array}$ & $\begin{array}{l}\text { Rehabilitation } \\
\text { and exercise as } \\
\text { motivation and } \\
\text { kickoff for daily } \\
\text { drudgery }\end{array}$ & $\begin{array}{l}\text { The need for } \\
\text { continuity and } \\
\text { competent } \\
\text { facilitation }\end{array}$ \\
\hline $\begin{array}{l}\text { "I was offered a stay right away when } \\
\text { they discovered it. Could get time off } \\
\text { from work too. But I didn't do it!" }\end{array}$ & $\begin{array}{l}\text { Was offered, did not } \\
\text { accept }\end{array}$ & $\begin{array}{l}\text { Offered } \\
\text { rehabilitation }\end{array}$ & & & \\
\hline $\begin{array}{l}\text { "I have a terrific nice doctor, but he } \\
\text { knows nothing about COPD. It's not } \\
\text { even a topic. The hospital does the } \\
\text { follow-up. But he's really nice in every } \\
\text { other way." }\end{array}$ & $\begin{array}{l}\text { Terrific nice } \\
\text { physician, lacked } \\
\text { knowledge on COPD } \\
\text { follow-up at hospital }\end{array}$ & $\begin{array}{l}\text { Primary physician's } \\
\text { lack of specialist } \\
\text { knowledge }\end{array}$ & $\begin{array}{l}\text { Collaboration } \\
\text { with the primary } \\
\text { physician }\end{array}$ & $\begin{array}{l}\text { When COPD is } \\
\text { not a topic with the } \\
\text { primary physician }\end{array}$ & \\
\hline
\end{tabular}

project group with a focus on central findings. Following dialogue in several meetings, the categories were developed further into themes (step 4, the latent meanings), in light of the research questions. The article manuscript was collaboratively developed in the research group (Table 1).

\section{Ethics}

The study was recommended by the Regional Committees for Medical and Health Research Ethics - West (2013/1301) and approved by Førde Hospital Trust (2013/5651). All co-researchers signed confidentiality agreements. The study participants received written information and gave written informed consent for this study.

\section{Results}

The final sample consisted of six males and five females, aged 62-76 years, with CAT scores of 21-29 (high symptom burden). All lived at home without assistance with day-to-day self-management (Table 2).

The interviews gave the impression that a good life was possible with COPD, as long as the patient learned to live with, and adapt to, the changes that arose. All respondents had had to adjust their social roles and participation, and they spent a lot of time on self-management. Great selfeffort, motivation, and taking charge of their exercise and self-management emerged clearly. The respondents were also concerned with the development of the illness and with preventing and handling exacerbations. The episodes of exacerbation demanded much energy, especially in case of acute hospital admissions. Getting to know their new body and reactions was important to successful self-management. The participants said this was time-consuming.

The sample showed great variation with regard to what services the participants had received from the healthcare 
Table 2 Sample characteristics

\begin{tabular}{|c|c|c|c|c|c|c|c|}
\hline $\begin{array}{l}\text { Genderl } \\
\text { participant } \\
\text { number }\end{array}$ & Age & $\begin{array}{l}\text { Education } \\
\text { years }\end{array}$ & Cohabitance & $\begin{array}{l}\text { COPD } \\
\text { years }\end{array}$ & $\begin{array}{l}\text { CAT } \\
\text { score }\end{array}$ & Smoking & Health-care utilization \\
\hline Male/I & 62 & $>11$ & Children & 15 & 21 & No & $\begin{array}{l}\text { Physiotherapy } \\
\text { Rehabilitation } \times 5 \\
\text { SME } \times 2 \\
\text { Health controls } \\
\text { SHS }\end{array}$ \\
\hline Male/2 & 67 & $<\mathrm{II}$ & Wife & 3 & 19 & Yes & $\begin{array}{l}\text { Health controls } \\
\text { PP }\end{array}$ \\
\hline Female/3 & 69 & $>11$ & Husband & 10 & 21 & No & $\begin{array}{l}\text { Physiotherapy } \\
\text { SME } \\
\text { Health controls } \\
\text { SHS }\end{array}$ \\
\hline Male/4 & 63 & $<11$ & None & 7 & 26 & Yes & $\begin{array}{l}\text { Occupational therapy } \\
\text { SME } \\
\text { Health controls } \\
\text { SHS } \\
\text { Health controls } \\
\text { PP }\end{array}$ \\
\hline Male/5 & 70 & $>11$ & Cohabitant & II & 25 & Yes & $\begin{array}{l}\text { Health controls } \\
\text { SHS }\end{array}$ \\
\hline Female/6 & 67 & $<\mathrm{II}$ & Husband & 17 & 26 & No & $\begin{array}{l}\text { Rehabilitation } \times 2 \\
\text { SME } \\
\text { Health controls } \\
\text { SHS }\end{array}$ \\
\hline Female/7 & 70 & $>11$ & None & 4 & 29 & No & $\begin{array}{l}\text { Physiotherapy } \\
\text { Rehabilitation } \times \text { I } \\
\text { Smoking cessation } \\
\text { Health controls } \\
\text { SHS } \\
\text { Acute hospital admission } \times I\end{array}$ \\
\hline Male/8 & 64 & $>11$ & Cohabitant & 30 & 25 & Yes & $\begin{array}{l}\text { Physiotherapy } \\
\text { SME } \\
\text { Rehabilitation } \times \text { I } \\
\text { Smoking cessation } \\
\text { Health controls } \\
\text { SHS } \\
\text { Acute hospital admission } \times 3\end{array}$ \\
\hline Female/9 & 71 & $<\mathrm{II}$ & None & 5 & 21 & No & $\begin{array}{l}\text { SME } \\
\text { Health controls } \\
\text { SHS } \times 3\end{array}$ \\
\hline Female/I0 & 76 & $<\mathrm{II}$ & Husband & 10 & 24 & No & $\begin{array}{l}\text { Health controls } \\
\text { PP }\end{array}$ \\
\hline Male/II & 70 & $<\mathrm{II}$ & $\begin{array}{l}\text { Wife, } \\
\text { daughter }\end{array}$ & 18 & 24 & No & $\begin{array}{l}\text { SME } \\
\text { Smoking cessation } \\
\text { Health controls } \\
\text { SHS }\end{array}$ \\
\hline
\end{tabular}

Abbreviations: CAT, COPD assessment test; SME, self-management education; SHS, specialist health care service; PP, primary physician.

services in order to manage their disease and develop good self-management. The participants who had been through rehabilitation as inpatients or received self-management training in the "learning and coping centers" described these as turning points. New knowledge was important to being able to handle, develop, and maintain self-management. Continuity and access to competent health personnel also appeared essential to gaining an experience of sufficient support in self-management. The majority of participants found the competence they needed in the specialist healthcare services, and those that had been in contact with the specialist healthcare services wanted long-term support from these services. The participants reported that their primary physician played a small role in their follow-up. Encounters with 
health personnel who did not know, examine, or understand the participants' situation were experienced as critical events and threats to good transitions.

The content of the interviews is analyzed into two main themes and eight subthemes. The themes are presented in the following and documented with quotes.

- The struggle to keep going

- The challenges of changing social roles and function

- The demanding exacerbations and critical events

- Getting to know "the new vulnerable self"

- Taking charge of exercise

- The need for continuity and competent facilitation

- Rehabilitation and training as a kickoff for the everyday drudgery

- Competent helpers to contact

- When COPD is not a topic with the primary physician

- The emergency room with no idea of what is going on

\section{The struggle to keep going}

The illness had caused changes in roles and function, and the participants had had to adapt and plan their daily lives in a different way. In order to move on, they had over time learnt self-management and other techniques adapted to stable and less stable periods.

The challenges with changing social roles and function Getting COPD, the diagnosis as well as the functional impairment that goes with it, had changed the participants' everyday life, what they did, and how they lived. None of the participants were working. The changes in roles and social participation were related to family, leisure activities, travel, and daily activities. This at times constituted quite a challenge:

I was quite involved before, volunteering and hunting and fishing and all, this is all over now, when I can no longer keep up I feel like a burden. [4]

Within the family, a gap may also develop between the expectations of others and what the participants were able to do:

I really notice it when I'm with the grandchildren. They are just so active (laughs). It doesn't show, you know. And they do expect you to join in [...]. I still try to find ways to get around this with them.

This participant struggled on several fronts:

For it (the illness) does slow you down quite [...] a lot. I like traveling, but that's getting increasingly difficult.
I am quite stubborn though, I'm not willing to give up, I've tried to live like I've always done, but I'm gradually unable to do that. [3]

When the illness gradually demanded aids, it became visible to all that the participants were seriously ill. One woman had great problems getting around, but even greater problems with using a wheelchair and oxygen equipment:

I do have a wheelchair, you know. This is the sort of thing I struggle with. I got it last year, I think, no, two years ago. We came home from Southern Europe. [...] I couldn't do a thing. We talked about me going to the hospital. [...] They said: "Get a wheelchair, that will make it much easier for you when you have to go far."

So, we applied for one, and got it too. [...] And now I have to start using oxygen. I just hate the thought of it. He [the physician] said I have to use it day and night. But I'm just saying that when we go to where we usually have dinner and shop for food. I'm just not using the oxygen. I was really clear on this. I don't remember what he answered. But I am just not doing that! I am not going to sit there, in public, with that thing up my nose and eat. It is probably stupid of me, but [...]. [6]

Having one's identity changed to "the person with COPD" had also caused some negative emotions regarding self-inflicted illness:

Well, and then there's the guilt, you know? I really felt that so strongly at first. Didn't want to tell anyone. It's terrible, isn't it (laughs). I still think that way, even if it has changed over the past ten years. That you, as you say, push it away, don't want to talk about it. Well, I'm more at ease with all that now, but I don't go around telling people I have COPD, unless I have to. I just really don't [...]. And that may have to do with that as a group we sort of have a feeling that we are not taken as seriously as others? Maybe there's something there? [3]

The COPD diagnosis also had negative associations in relation to prognosis:

When I hear the word COPD I think it's just horrible. Just as if there's something terrible that goes with it. For you think you'll be really sick, you won't be able to breathe and $[\ldots] .[10]$

The doctors say lung emphysema. I really didn't understand how dangerous this was. Had they said COPD at once, however [...] I hear that is bad. But I didn't understand what it was, so I was pretty calm at first. [11] 
The COPD diagnosis was accompanied by more such changes: impaired functioning, changing roles, and poor prognosis.

\section{The challenge of exacerbation and critical events}

All participants had had serious episodes with difficult breathing and exacerbation, but with varying frequency and severity. Only two of them had had acute hospital admissions with COPD the past year. Such experiences were frightening and challenging. Repeated acute admissions in particular were experienced as critical:

There was a lot of trauma related to all the admissions. It was all very tiring, and [...] I suffered a lot from depression and anxiety, and last time three years ago, I was so sick that I had one and a half foot in the grave. The doctors said there was not much to do. I fought and fought [...]. [1]

This participant had not been able to quit smoking, and that bothered him when he was in the hospital:

I snuck along the walls there. Felt just so guilty that I was occupying a bed. But the nurses said: no, you do have the right to be here. But I said, can't they just have my bed? It was horrible; my mental health was poor too. I tried to make myself so small that they wouldn't notice me. I was never in bed. [1]

Short episodes of heavy breathing were also experienced as critical after many years of illness, even though managing such episodes gradually became part of daily life:

It is the cough, you know, and the breathing. [...] I've woken up during the night and not been able to breathe. Well, it is a bit scary, isn't it, when you can't breathe. [11]

\section{Getting to know the "new vulnerable self"}

The participants emphasized knowledge and experience over time as important in developing self-management skills. Even though all interviewees stated that by and by their daily life was pretty good, living with COPD was fatiguing:

You are so vulnerable. You have a disease that wears you down each and every day! [1]

Through daily efforts and accommodations by the healthcare services, self-awareness grew:

I gradually gained pretty good self-knowledge, especially after a stay at the rehabilitation unit. I guess I understood more about my own disease and that's important. And I probably still didn't understand how this was going to turn out, but the path gradually emerged. [1]
Several times, the patient initiated what became new knowledge:

And it was my own initiative that got me this (rehabilitation). I got the doctor to apply - I am somewhat curious by nature. I want to know what's the latest. Both on medication and on what you can do yourself to stay healthy as long as possible and as well as possible. [3]

The challenges with breathing and respiratory problems in particular were mentioned; these had to be considered every day:

How it is? It is really shitty. [...] It has gotten worse over the past two years. But then again, you just don't get any younger, do you. [4]

Experience was needed to get through episodes of heavy breathing:

I knew nothing about breathing techniques. I use lip breathing [...]. After all, you don't die right there and then.

Even if you may think so. But there is something about learning that too. That's how far it goes. [2]

Those who had been ill for a longer period were able to do a lot on their own. They knew their symptoms and the medication, and as long as they could have medications available for use in periods of exacerbation, they felt safer:

I don't go see a doctor. You know, I've had this for 20 years.

I can tell by my breathing [...] I have those pills; antibiotics and I take cortisone [...] But I do know my body. [7]

The dosing of inhalations was also difficult to understand, and misunderstandings arose:

I took too much of those too, you know. When I told the doctor about the medications I was on it blew his mind. For the one I took five times a day he had said I could use up to six times. But what he probably meant was when I got worse. And I hadn't quite caught that. [7]

\section{Taking charge of exercise}

All participants attended some exercise class or did other regular physical activity: hiking, walking groups, fitness studio, swimming, dancing, etc. They voiced great responsibility and commitment, and their motivation was avoiding exacerbation of their illness. The physical activity required a positive attitude:

Yes, keep going! Even if you get knocked down once or twice in life, try looking to the future. Don't look back and feel sorry for yourself. I think that's incredibly important. 
And to have some follow-up at least once a year with breathing test and x-rays and getting to know how things are going, even if I don't feel I'm getting worse. [6]

Keeping up former activities was also possible with some adjustments:

I have always liked walking in the woods. But then I get $[\ldots]$ have to walk some, stop for a bit and [...] I exercise three times a week. Then I exercise as much as I'm able to and that has made my life completely different. I sort of have a good conscience. It's just really good to go in there too. I feel I can't cut classes. So, all in all I'm pretty active. I feel it helps me quite a bit, being like that. [9]

Even with oxygen dependence, a participant could exercise quite a bit at home if the proper equipment was available:

Now I'm building myself up on the "step-up." I'm now at 30 steps, and I have to increase. I'm really going to get up there! It's like walking stairs. And each of these weights is four kilos, and I have no problem with that. I do this five days a week. I take two days off. Don't you think that's pretty good? [...] You know, I have exercised on my own the whole time, for I've figured that's something nobody can do for me [...] I don't mind, for I know what it's like when I don't do it. [6]

\section{The need for continuity and competent facilitation}

The services and follow-up the participants had received from the healthcare services varied considerably. The findings contain experiences from rehabilitation stays and shorter self-management courses. Some have had several stays in rehabilitation, others none. Some were followed up by the specialist healthcare services, some not, and the primary physicians had a modest role in the follow-up.

\section{Rehabilitation and exercises as a kickoff for the everyday drudgery}

Three participants had been to rehabilitation, and five had participated in self-management education. The majority had taken the initiative themselves to get rehabilitation, but some also remembered having been recommended rehabilitation early in their disease trajectory without accepting:

And for this I took the initiative myself. I got the doctor to apply. You had to ask. But that nurse did encourage me to do so several times. I'll say that. [3]
I was offered a stay right away when they discovered it. Could get time off from work too. But I didn’t do it! [8]

New knowledge on disease and guidelines was useful, and the rehabilitation stay, or self-management course also included medical examination by specialists:

That's the point of the COPD school (self-management education), that you are examined and then the course. It's a minimum and really important. I was mostly concerned with the medical side of it. You get some insight into this and what's going to be important in the future. So, I'll say it should be a standard program from doctors - for everybody [...] What's most important? I don't know. Maybe - all this about exercise and adjustments in day to day life. [3]

A rehabilitation stay helped in several ways, and those who had had such a stay wanted to repeat it to get good follow-up and renewed energy:

There are several things. One is that at home you get to choose whether you want to get on the treadmill or not. But there you just have to every morning. It gives sort of a kick-start. [1]

You were followed up all the way, they addressed the problems you have. It's not just the COPD and the lungs. [7]

\section{Competent helpers you can get in touch with}

Those who had attended local self-management courses gained knowledge and received guidance, and made contacts that gave possibilities for further follow-up:

That we get so close to the nurse in such a setting. So, it's more intimate and we want to do more [...] And then it's really important that you have that COPD-school nearby, right $[\ldots]$ ? I think this setting here is really good. You have something to gain as a user. You make contacts. [1]

These participants had yearly checkups at the outpatient clinics afterward, and they had great confidence in the personnel there:

Those guys in the hospital know what they're doing, and they collaborate with the doctors. [2]

Several participants had got to know the lung specialists quite well and had developed trusting relationships:

She was so that you could talk about anything. Almost like a buddy [...]. [8]

He was just so good at talking to us, we just really understood it all. Then he said: There's this one thing. If a COPD patient comes to me and says he is not anxious or 
nervous or anything, he lies. For that comes with the territory. I really liked hearing that. [1]

When one of the specialists quit, the continuity of the follow-up by physician felt like a loss:

But when it comes to COPD I've been followed up by a specialist once a year. I was really happy with that. If some acute problem arose, I could just call. But now I have nobody, since her, for nothing has happened. I'm a bit disappointed with that [...] Yeah, I'm no longer in the system! [7]

Being able to get in touch directly gave a feeling of security, especially in periods of exacerbation when hospital admission seemed necessary:

Well, things are fine now that I have a direct number to call. [2]

And then I have the nurse at the outpatient clinic whom I can text if I worry about the phlegm, etc (laughs), I've got really good follow-up there. I don't go there other than if I have a fever, then it's ok. I'm really scared to get pneumonia. I've never been admitted with that. [6]

It was very important for all participants to get to know how the physical parameters had changed since last time, they knew they had a progressive disease, and they feared exacerbation:

$[\ldots]$ just great to have a checkup once a year. Then I know how I'm doing. [11]

But getting the results might be scary too:

I'm just like - I don't want to know my lung capacity. Or I'll just go around speculating and speculating. [...] Not if it has improved either? [...] Well, I won't mind being told that, but I don't need to know by how much. [2]

\section{When COPD is not a topic with the primary physician}

All participants had their own primary physician, and most of them were in touch with him or her now and then.

I have a terrific nice doctor, but he knows nothing about COPD. It's not even a topic. The hospital does the follow-up. [6]

Several participants expressed a lack of confidence in their primary physicians' COPD competence:

No, they know nothing. They know so little. But we probably shouldn't blame them too much. They have more than enough. And a group like chronically ill patients $[\ldots]$ there should be some warning lights and they should pay a bit more attention than they do. Yeah, and I'm the one who has told him that there is a plan for stepping up medication. [1]

Those who received good follow-up by the outpatient clinics did not need to consult their primary physician with regard to $\mathrm{COPD}$, other than to renew prescriptions from the specialist healthcare services, and in some instances, referrals to rehabilitation:

I don't go there for my COPD in particular. But we do talk about it. But I don't contact him much about that. But I told him that I had decided to go to rehabilitation. He sent in an application and I got an answer. [8]

Nevertheless, continuity in the primary physician follow-up seemed to be important:

And then I lost my primary physician. I was in limbo. [7]

\section{The emergency room has no idea what is going on}

At episodes of exacerbation, common procedure was that the patients had to go through the emergency room where the physicians did not have access to the patient's journal, and thus generally no knowledge of the patients' prior problems:

But when I go to the emergency room [...]. May stay there some three or four hours. Then it's the same procedure. And I say: Yeah, but are x-rays really necessary, I've been here five or six times this year? It says right there. Then I think: is that necessary? How many x-rays am I to have? There is some risk associated with that too. It's the same thing that happens to me, nothing new there. That scares me. I sort of feel that it's not something I decide, the routines decide. I feel maybe there should be some dialogue with someone who explains to me that now it is important to [...], it is important that we get an x-ray of you. [1]

Especially when one feels critically ill, but is not believed and taken seriously, that is experienced as a violation:

To me it was very important to be believed. That now I am that sick! They could tell by looking at me, you know. It was nothing dramatic, right, but [...]. [1]

These findings describe important phenomena in the participants' interaction with the healthcare services. There was great variation in what healthcare services the participants had received, from whom, and how satisfied they were with the interaction with the individual healthcare worker. 


\section{Discussion}

The purpose of this study was to explore how persons living with COPD experience transitions related to health, selfmanagement, and follow-up from the healthcare services. The central experiences with transitions in health and selfmanagement emerge from the descriptions of the struggle to keep going through changing social roles and function, through exacerbations and critical events, and through getting to know and taking charge of one's own health. The participants, who lived with COPD, emphasized knowledge and competent interaction with the healthcare services as necessary for accommodating transitions, while the absence of access to specialist competence hindered transitions.

The interviews clearly show that receiving the COPD diagnosis, the consequences of the disease, and interaction with relatives and the healthcare services have resulted in great changes and challenging transitions. Several studies claim that COPD has a poor prognosis and that facing the diagnosis leads to experiences as a stigma with guilt and shame. ${ }^{18}$ Data from this study support this perspective. Receiving the diagnosis was a critical event for several participants and initiated a transition, ${ }^{2}$ both because the diagnosis was associated with a poor prognosis and because it was experienced as a stigma with guilt and shame. For some, the diagnosis thus initiates a vulnerable period, where fear and experience of stigma may keep patients from seeking the help they need to move on. Despite long-term focus on the negative effects of stigmatization on the person's quality of life, ${ }^{18,19}$ the findings show that the problem still exists for people who live with COPD, even if the findings also describe a further transition toward greater acceptance and less stress for the participant quoted. The findings also clearly show that receiving the diagnosis, having to use medical aids, and being unable to participate in social activities like before constituting great changes and are threats to identity ${ }^{15}$ and social participation. The transition to a new role and new social positions demands adaptation over time in interaction with the surroundings. ${ }^{2}$ A cultural norm in society or in the person himself that stigmatizes COPD as self-inflicted may hinder transitions toward growth and improved health. Heggdal $^{39}$ emphasized that people who live with chronic diseases must learn to put into words the challenges related to social interaction; this is very relevant in the case of a disease that may give an experience of stigmatization, of low self-worth, and where the functional impairment may be both invisible and very visible if medical aids like oxygen are used. Using oxygen may give an experience of improved health, function, and social activity, as well as challenges such as an increase in practical organization, dependence, and embarrassment. ${ }^{40}$ This study reports only experiences of the challenging and negative aspects of using oxygen. Challenges related to social interaction and changing roles, including interaction with the healthcare services, should make up part of self-management education, ${ }^{4}$ and focus on possible experienced stigmatization, and consequences of using oxygen should be included in such follow-up. Not all participants in this study had received self-management education or rehabilitation, even though this is recommended in the healthcare services. ${ }^{6,10}$

Positive findings, however, are that all participants described having a good daily life, after having managed to adapt to the demands for changes. Their self-management skills developed over time as they became more familiar with their own vulnerability and boundaries. People living with COPD may develop good self-management skills on their own. ${ }^{41}$ This study nevertheless shows quite clearly that rehabilitation and self-management education were experienced as important facilitators for self-management and the transition to managing the consequences of the disease, in accordance with studies that have shown that self-management education may improve quality of life and increase coping ability in the short run. ${ }^{24,25,42}$ But despite the development of self-management competence, the findings show that dyspnea episodes in particular may be experienced as a threat in daily life even after many years of living with the disease. Adapting to dyspnea episodes seemed like a transition in itself. A new and important finding is the experience of guilt at exacerbation and acute admission to hospital. Being unable to quit smoking and manage the disease was experienced as not meeting the healthcare personnel's expectations for patients' self-management. The ideals of self-management may thus increase the burden of people living with the disease, with threats of developing negative identity and nega-

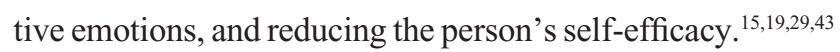
Another important finding is the participants' emphasis on being able to initiate medicinal treatment on their own; this helped give them an experience of a certain control at exacerbation episodes which are important in a common COPD trajectory, with great costs to the individual and the health services. ${ }^{44}$ Self-management should be collaborative with the patient as an equal participant. ${ }^{5,21}$ Having access to start medication in case of exacerbation may be a clear signal of trust from the physician, may facilitate transition to a new identity with an active patient role, ${ }^{15}$ and give a good basis for collaborative self-management. ${ }^{4}$ Also important in selfmanagement of COPD are physical activity and exercise. 
The findings describe the participants' great commitment to and responsibility for exercise, and their motivation was to slow down the progression of the illness. Being able to carry out recommended exercise made them proud and happy, which give positive associations to self-management skills $^{45}$ and seemed to support a positive identity, mastery, and self-efficacy, indicators of a health-enhancing transition. ${ }^{2}$ However, patients who are unable to achieve this would rather become invisible. This may be interpreted as if the healthcare services have too high expectations, and the individual responsibility may be too great, and thus become an obstacle to a good health transition.

All participants interacted with the healthcare services, and this interaction seemed to be of great importance. There was great variation in the follow-up services the participants reported having received, even if they all lived within a geographically limited area and all were covered by the same national guidelines. ${ }^{10}$ Both self-management courses and rehabilitation stays were found to be useful and necessary facilitators for self-management development and transition toward management of everyday challenges. Offers of rehabilitation and exercise sometimes originated in the healthcare services; at other times, the participants had taken the initiative. One participant stated that he did not accept the offer, and in retrospect, seemed surprised at this. This indicates that the participant was not aware of the changes or was in transition $^{2}$ when he received the offer, and therefore did not accept it. Others wanted, and took the initiative to get, rehabilitation several times, to learn something new or to increase their motivation for exercise and other self-management skills. Real-user collaboration requires individualized and timely services. A COPD trajectory is winding and progressive, and exercise and rehabilitation must be adapted to the various phases. ${ }^{3}$ Health status is negatively associated with self-management activation, ${ }^{27}$ and the absence of facilitation in the form of new learning throughout the illness trajectory may therefore lead to stagnation and inadequate selfmanagement. Several participants expressed fear of acute exacerbation and seemed to know well how important quick treatment is. Important findings are the participants' emphasis on establishing contacts with competent healthcare workers in the community and having "a direct line" to them, as this would make it easier to make contact if problems arose. The participants also wanted annual checkups on their disease, to confirm or reject any progression. These are good examples of how access to the healthcare services, social support, and confidence with regard to getting help $p^{2,5,16}$ improve health in a COPD trajectory. The participants' assessment of the helpers' level of insight into the problems associated with COPD emerged as an important phenomenon in the creation of trust in the interaction. This was the case for specific somatic medical knowledge, as well as familiarity with common psychological-associated conditions. Contact with primary physicians or emergency room physicians who did not appear to have sufficient competence did not create trust; this may also be experienced as not being believed and affected the participants' confidence and self-management negatively. Such lack of trust may complicate collaborative self-management, even if the healthcare worker is on the "supply side". The intention in the Norwegian Coordination Reform $^{11}$ is that the municipal healthcare services and the primary physicians shall handle follow-up services in the case of long-term diseases. However, if the patients do not trust the competence of the primary physicians, as this study shows, collaboration becomes difficult, and the participants would rather consult the specialist healthcare services if they had contacts there. A paradox was that they nevertheless wanted continuity in the follow-up by their primary physician. Continuity in the follow-up strengthened the relation and collaboration, based on both personal knowledge and that the healthcare worker was more familiar with the patient's situation. Such relations seemed to strengthen the participants' self-confidence. Positive identity and experience of user participation may contribute to the collaboration, in keeping with the intention of the Coordination Reform. ${ }^{11}$ As Hillebregt et $\mathrm{al}^{23}$ have earlier shown, the implementation of collaborative self-management was a complex process dependent on the patient, healthcare personnel, and the organization of the services. As such, this finding is in accordance with our study and the Norwegian context.

\section{The study's reliability}

The concepts of credibility, dependability, and transferability are used in assessing the quality of qualitative studies. ${ }^{38}$ The credibility of this study was strengthened by the participatory design ${ }^{30}$ with considerable user involvement. The co-researchers' input had consequences for the research focus, interview guide and interviews, and in the process of analysis with repeated equal discussions in the project group, where we emphasized the collective learning process, ${ }^{33}$ collaborative climate, and division of power, ${ }^{34}$ and in this way strove for optimal relevance of the study, and thus, benefit for persons living with COPD. The co-researchers' participation had to be negotiated ${ }^{34}$ and limited based on their capacity, as they expressed that participation was demanding. Throughout the whole analysis process, we emphasized 
reflexivity in particular through exploring the team members' preunderstanding, and the influence of the preunderstanding on the interpretation of data, and during interpreting the data based on the interview participants' stories and contexts. ${ }^{46}$ The correlation between units of meaning, category, and theme is documented in Table 2. The interview participants had varied background and varied experiences (Table 1), and they gave rich descriptions in the interviews; this strengthens the study's credibility. ${ }^{36}$ A limitation is that the participants were all from a limited geographical area and had a symptom burden within a certain interval of the CAT scores. Dependability refers to the stability of the data, influenced by how the interviews were conducted. ${ }^{36}$ In the interview situations, the co-researchers also communicated their own experiences, which led to discussions and exploration of questions and answers. This might have influenced the data; however, to our opinion, the interviews were characterized by openness and common interest for themes, and the discussions strengthened the dependability of the data. To increase the transferability of the study, we have presented the data with illustrative quotes, the sample is closely described, and the analysis process is transparently documented.

\section{Implications for practice}

The study's findings contribute to our understanding of the patients' complex transitions in a COPD trajectory, and thus, offer guidance regarding timing and quality of follow-up services. The findings support recommendations that all who receive the diagnosis of COPD must be offered self-management training, rehabilitation, and follow-up. This, however, does not seem to be common practice in the context of this study, in spite of recommendations in guidelines. Information and conversations on challenges related to stigmatization, disease-specific self-management requirements, and social interaction are relevant topics to focus in self-management education. The timing of these services should be adapted to whether the person is in transition. We recommend counseling with assessment of experienced needs and motivation for learning and change. Counseling and offers of services should be repeated for the users to find the appropriate time for them to join programs, throughout the disease trajectory as health status and learning needs keep changing. Follow-up of the development of the disease should be done on a regular basis, with attention to the positive, motivating clinical test results. On the other hand, negative clinical test results may have the opposite effect on motivation to self-management and exercise. In order to implement the intention of the Coordination Reform and national guidelines for COPD patients, there must be personnel with sufficient competence and resources for regular and competent assessment and follow-up in the primary healthcare services. The possibility for direct contact with healthcare workers with special competence is an advantage. When it comes to research and quality improvement of services, we recommend a participatory design when studying follow-up services. Service user involvement has the potential to strengthen the credibility of the research process and relevance of results. We advise that the coresearcher involvement should be adjusted to the capacity of each service user.

\section{Conclusion}

The study yields a deeper understanding of transitions associated with health and self-management challenges for people living with COPD and offers clinicians guidance for the timing and quality of follow-up services. Transitions with vulnerable phases and great changes associated with role, function, exacerbation episodes, and social interaction are demanding and place great demands on self-management. Offers of, and participation in, self-management education and rehabilitation that also address psychosocial challenges related to the disease at the right time, and at changing self-management needs, may facilitate health-enhancing transitions and improve self-management skills. Experienced lack of competence in health workers and lack of flexibility affect trust and collaboration negatively. Access to stable and competent follow-up in the primary healthcare services can facilitate collaborative self-management and support in accordance with the intentions in the Norwegian Coordination Reform and national guidelines on follow-up of chronic diseases in the primary healthcare services.

\section{Acknowledgments}

The authors want to thank the rest of the collaborative team, Grete Berg Grimelid, Tone Larsen, and Aud Berit Fossøy. Service user Steinar Valvik died last November. The team is especially grateful for his contribution until he passed away. The authors are also grateful to and want to thank all service users who participated in the study. The project has been supported by the Norwegian ExtraFoundation for Health and Rehabilitation.

\section{Disclosure}

The authors report no conflicts of interest in this work. 


\section{References}

1. Meleis AI, Sawyer LM, Im EO, Hilfinger Messias DK, Schumacher K. Experiencing transitions: an emerging middle-range theory. ANS $A d v$ Nurs Sci. 2000;23(1):12-28.

2. Meleis A. Transitions Theory Middle-Range and Situation-Specific Theories in Nursing Research and Practice. New York: Springer Publishing Company LLC; 2010.

3. Bourbeau J. The role of collaborative self-management in pulmonary rehabilitation. Semin Respir Crit Care Med. 2009;30(6):700-707.

4. Bourbeau J, Saad N. Integrated care model with self-management in chronic obstructive pulmonary disease: from family physicians to specialists. Chron Respir Dis. 2013;10(2):99-105.

5. Halding AG, Heggdal K. Patients' experiences of health transitions in pulmonary rehabilitation. Nurs Inq. 2012;19(4):345-356.

6. GOLD. Global strategy for the diagnosis, management and prevention of COPD. Updated 2017. Available from: http://goldcopd.org/ gold-2017-global-strategy-diagnosis-management-prevention-copd/. Accessed April 05, 2018.

7. World Health Organization. Global Health Observatory (GHO). 2017. Available from: http://www.who.int/nmh/countries/nor_en.pdf?ua=1 Accessed February 10, 2018.

8. American Lung Association. Trends in COPD (chronic bronchitis and emphysema): morbidity and mortality. Research and Health Education Division, Epidemiology and Statistics Unit, American Lung Association; 2013. Available from: http://www.lung.org/assets/documents/ research/copd-trend-report.pdf. Accessed December 12, 2017.

9. Kim V, Crapo J, Zhao H, et al. Comparison between an alternative and the classic definition of chronic bronchitis in COPDGene. Ann Am Thorac Soc. 2015;12(3):332-339.

10. The Norwegian Health Directorate. Kols. Nasjonal faglig retningslinje og veileder for forebygging, diagnostisering og oppfølging [COPD. National guidelines for prevention, diagnosing and follow-up]. 2012 Available from: https://helsedirektoratet.no/retningslinjer/nasjonalfaglig-retningslinje-og-veileder-for-forebygging-diagnostisering-ogoppfolging-av-personer-med-kols. Norwegian. Accessed November 12, 2017.

11. The Norwegian Ministry of Health and Care Services. Samhandlingsreformen [The Coordination Reform]. Report No. 47. 2008-2009. Available from: https://www.regjeringen.no/no/dokumenter/stmeldnr-47-2008-2009-/id567201/. Norwegian. Accessed November 03, 2017.

12. Lorig KR, Holman H. Self-management education: history, definition, outcomes, and mechanisms. Ann Behav Med. 2003;26(1):1-7.

13. Benner P. Foreword. In: Meleis A, editor. Transitions Theory: MiddleRange and Situation Specific Theories in Nursing Research and Practice. New York: Springer Publishing Company; 2010:xiii-xiv.

14. Kralik D, Visentin K, van Loon A. Transition: a literature review. J Adv Nurs. 2006;55(3):320-329.

15. Charmaz K. Loss of self: a fundamental form of suffering in the chronically ill. Sociol Health Illn. 1983;5(2):168-195.

16. Nanton V, Munday D, Dale J, Mason B, Kendall M, Murray S. The threatened self: considerations of time, place, and uncertainty in advanced illness. Br J Health Psychol. 2016;21(2):351-373.

17. Doos L, Bradley E, Rushton CA, Satchithananda D, Davies SJ, Kadam UT. Heart failure and chronic obstructive pulmonary disease multimorbidity at hospital discharge transition: a study of patient and carer experience. Health Expect. 2015;18(6):2401-2412.

18. Rose S, Paul C, Boyes A, Kelly B, Roach D. Stigma-related experiences in non-communicable respiratory diseases: a systematic review. Chron Respir Dis. 2017;14(3):199-216.

19. Halding AG, Heggdal K, Wahl A. Experiences of self-blame and stigmatisation for self-infliction among individuals living with COPD. Scand J Caring Sci. 2011;25(1):100-107.

20. Kralik D, Kock T, Price K, Howard N. Chronic illness self-management: taking action to create order. J Clin Nurs. 2004;13(2):259-267.
21. Effing TW, Vercoulen JH, Bourbeau J, et al. Definition of a COPD self-management intervention: International Expert Group consensus. Eur Respir J. 2016;48(1):46-54.

22. Richard AA, Shea K. Delineation of self-care and associated concepts. J Nurs Scolarsh. 2011;43(3):255-264.

23. Hillebregt CF, Vlonk AJ, Bruijnzeels MA, van Schayck OC, Chavannes NH. Barriers and facilitators influencing self-management among COPD patients: a mixed methods exploration in primary and affiliated specialist care. Int J Chron Obstruct Pulmon Dis. 2016;12: $123-133$.

24. Wang T, Tan JY, Xiao LD, Deng R. Effectiveness of disease-specific self-management education on health outcomes in patients with chronic obstructive pulmonary disease: an updated systematic review and metaanalysis. Patient Educ Couns. 2017;100(8):1432-1446.

25. Johnson-Warrington V, Rees K, Gelder C, Morgan MD, Singh SJ. Can a supported self-management program for COPD upon hospital discharge reduce readmissions? A randomized controlled trial. Int $J$ Chron Obstruct Pulmon Dis. 2016;11:1161-1169.

26. Jonkman NH, Westland H, Trappenburg JC, et al. Do self-management interventions in COPD patients work and which patients benefit most? An individual patient data meta-analysis. Int J Chron Obstruct Pulmon Dis. 2016;11:2063-2074.

27. Halding AG, Grov EK. Self-rated health aspects among persons living with chronic obstructive pulmonary disease. Int J Chron Obstruct Pulmon Dis. 2017;12:1163-1172.

28. Korpershoek Y, Bos-Touwen ID, de Man-van Ginkel JM, Lammers JW, Schuurmans MJ, Trappenburg J. Determinants of activation for selfmanagement in patients with COPD. Int J Chron Obstruct Pulmon Dis. 2016;11:1757-1766.

29. Clari M, Matarese M, Alvaro R, Piredda M, De Marinis MG. Measurement properties of instruments evaluating self-care and related concepts in people with chronic obstructive pulmonary disease: a systematic review. Heart Lung. 2016;45(5):441-448.

30. Bergold J, Thomas S. Participatory research methods: a methodological approach in motion. Forum Qual Soc Res. 2012;13(1). Available from: http://www.qualitative-research.net/index.php/fqs/article/ view/1801/3334. Accessed June 09, 2018.

31. Beresford P. Understanding the other. From 'other' to involved: user involvement in research: an emerging paradigm. Nordic Soc Work Res. 2013;3(2):139-148.

32. Pollock A, St George B, Fenton M, Crowe S, Firkins L. Development of a new model to engage patients and clinicians in setting research priorities. J Health Serv Res Policy. 2014;19(1):12-18.

33. Collins K, Ison R. Dare we jump off Arnstein's ladder? Social learning as a new policy paradigm. In: Proceedings of PATH (Participatory Approaches in Science \& Technology) Conference; June 4-7, 2006; Edinburg.

34. Moltu C, Stefansen J, Svisdahl M, Veseth M. Negotiating the coresearcher mandate - service users' experiences of doing collaborative research on mental health. Disabil Rehabil. 2012;34(19):1608-1616.

35. Malterud K. The art and science of clinical knowledge: evidence beyond measures and numbers. Lancet. 2001;358(9279):397-400.

36. Kvale S. InterViews. An Introduction to Qualitative Research Interviewing. Thousand Oaks: SAGE Publications; 1996.

37. Rowan M, Huston P. Qualitative research articles: information for authors and peer reviewers. CMAJ. 1997;157(10):1442-1446.

38. Graneheim UH, Lundman B. Qualitative content analysis in nursing research: concepts, procedures and measures to achieve trustworthiness. Nurse Educ Today. 2004;24(2):105-112.

39. Heggdal K. Kroppskunnskaping: Pasienten som Ekspert i Helsefremmende Prosesser [Bodyknowledging: Patients as Experts in Health-Promoting Processes]. Oslo: Gyldendal Akademisk; 2008. Norwegian.

40. Goldbart J, Yohannes AM, Woolrych R, Caton S. 'It is not going to change his life but it has picked him up': a qualitative study of perspectives on long term oxygen therapy for people with chronic obstructive pulmonary disease. Health Qual Life Outcomes. 2013;11:124. 
41. Gullick J, Stainton M. Living with chronic obstructive pulmonary disease: developing conscious body management in a shrinking lifeworld. J Adv Nurs. 2008;64(6):605-614.

42. Jonkman NH, Schuurmans MJ, Groenwold RHH, Hoes AW, Trappenburg JCA. Identifying components of self-management interventions that improve health-related quality of life in chronically ill patients: systematic review and meta-regression analysis. Patient Educ Couns. 2016;99(7):1087-1098.

43. Clari M, Ivziku D, Casciaro R, Matarese M. The unmet needs of people with chronic obstructive pulmonary disease: a systematic review of qualitative findings. COPD. 2018;15(1):79-88.
44. Mantero M, Rogliani P, Di Pasquale M, et al. Acute exacerbations of COPD: risk factors for failure and relapse. Int J Chron Obstruct Pulmon Dis. 2017;12:2687-2693.

45. Benzo RP, Abascal-Bolado B, Dulohery MM. Self-management and quality of life in chronic obstructive pulmonary disease (COPD): the mediating effects of positive affect. Patient Educ Couns. 2016;99(4): 617-623.

46. Finlay L. Through the looking glass: inter-subjectivity and hermeneutic reflection. In: Finlay L, Gough B, editors. Reflexivity: A Practical Guide for Researchers in Health and Social Sciences. Oxford: Blackwell Science; 2003:103-119.

\section{Publish your work in this journal}

The International Journal of COPD is an international, peer-reviewed journal of therapeutics and pharmacology focusing on concise rapid reporting of clinical studies and reviews in COPD. Special focus is given to the pathophysiological processes underlying the disease, intervention programs, patient focused education, and self management protocols.

\section{Dovepress}

This journal is indexed on PubMed Central, MedLine and CAS. The manuscript management system is completely online and includes a very quick and fair peer-review system, which is all easy to use. Visit http://www.dovepress.com/testimonials.php to read real quotes from published authors.

Submit your manuscript here: http://www.dovepress.com/international-journal-of-chronic-obstructive-pulmonary-disease-journal 